\title{
Clues to the mechanism underlying dopamine cell death in Parkinson's disease
}

\author{
P JENNER \\ From the Parkinson's Disease Society Research Centre, University Department of Neurology, Institute of \\ Psychiatry and King's College Hospital Medical School, London UK
}

SUMmaRy The primary pathological change in Parkinson's disease is the destruction of dopamine containing cells in the zona compacta of substantia nigra. The cause of nigral cell death and the underlying mechanism remains elusive. However, the discovery of the selective nigral neurotoxin MPTP and its ability to inhibit mitochondrial energy metabolism via its metabolite $\mathrm{MPP}^{+}$and to generate superoxide radicals suggests processes by which nigral cell death might occur. Recent postmortem evidence in brain tissue from patients dying with Parkinson's disease also suggests the occurrence of some on-going toxic mechanism. This may be a free radical process stimulated by an excess of iron within subsantia nigra coupled to a generalised decrease in brain ferritin content. These data suggest altered iron handling occurs in Parkinson's disease which may lead to the generation of toxic oxygen species such as superoxide radicals. There is also evidence for an inhibition of mitochondrial function in the substantia nigra in patients with Parkinson's disease. So there may be 3 close association between the actions of the synthetic neurotoxin MPTP and the underlying cause of idiopathic Parkinson's disease.

There are widespread pathological and biochemical changes in the brain of patients dying with Parkinson's disease. ${ }^{2}$ The primary alteration appears to be a loss of dopamine containing cells in zona compacta of substantia nigra with a corresponding generalised loss of dopamine content throughout the forebrain. While the details of these changes are extensively documented $^{3}$ there has been little evidence as to the underlying cause of dopamine cell death or the mechanism by which dopamine cells degenerate. Many theories have been advanced (for example, involvement of viruses, aberrant metabolism of dopamine, involvement of neuromelanin) but none of these proven. More recently interest has centred on the manner in which endogenous or environmental toxins may be involved as a cause of Parkinson's disease. This stems from the discovery of the selective nigral toxin, 1-methyl-4phenyl-1,2,3,6-tetrahydropyrdine (MPTP) which was found to induce persistent Parkinsonism in man and other primate species by destroying dopamine containing cells within substantia nigra. ${ }^{4-9}$

The discovery of MPTP provided a major impetus for research into the cause of Parkinson's disease.

Address for reprint requests: Dr P Jenner, Department of Neurology, Institute of Psychiatry, De Crespigny Park, London SE5 8AF, UK.

Accepted March 1989
However, MPTP does not provide an exact mode of idiopathic Parkinson's disease since in genera neurotoxic effects are limited to substantia nigra an its corresponding losses of caudate-putamets. dopamine content. ${ }^{78}$ Overall other neuronal system $\vec{s}^{+} \infty$ do not appear to be involved and there is no occurrence of Lewy bodies as a marker of the process underlying idiopathic Parkinson's disease. ${ }^{10-12}$ One reason for the discrepancies between MPTP induced Parkinsonism and the idiopathic disease may relate to the age of the animals studied. In general, young adult primates are used in such experiments but where older animals have been employed the pathology has been more extensive, involving also the locus coeruleus and Lewy body like inclusions have been observed. ${ }^{13-15}$ However, MPTP has provided the most appropriate animal model of Parkinson's disease so far devised. It has found use as a test-bed in which to evaluate novel therapies for Parkinson's disease ${ }^{16-19}$ and also to evaluate long-term complications of levodopa treatment of Parkinson's disease. ${ }^{2021}$ Similarly, MPTP treated primates provide an ideal test-bed in which to evaluate the usefulness of the implantation of foetal nigral dopamine containing cells as a "cure" for Parkinson's disease. ${ }^{22} 23$ However, it may be one other aspect of the actions of MPTP which is the most important, namely the mechanism by which MPTP kills nigral dopamine containing cells. This may 
provide clues to the selective vulnerability of this cell group and to the pathological process underlying dopamine cell death in Parkinson's disease.

\section{Mechanism of action of MPTP}

Many important steps in the mechanism of action of MPTP have been uncovered. Following the administration of MPTP to primates it was found that another substance, namely, 1-methyl-4-phenyl-pyridinium species $\left(\mathrm{MPP}^{+}\right)$, and not MPTP itself, accumulated and persisted within the brain. ${ }^{24} 25$ The reason for this became clear when it was discovered that MPTP was an unexpected substrate for MAO ${ }^{26-28}$ So it appeared that $\mathrm{MPP}^{+}$rather than MPTP might be the neurotoxic species. Indeed, $\mathrm{MPP}^{+}$was actively accumulated by dopaminergic neurons since it is a substrate for dopamine reuptake mechanisms $\mathrm{s}^{29}$ and this accumulation may be enhanced by an association with neuromelanin. ${ }^{30}$ MPTP neurotoxicity could be prevented by prior treatment of animals with MAO B inhibitors, such as deprenyl, or dopamine reuptake blockers, such as nomifensine. ${ }^{31} 32$ Also, $\mathrm{MPP}^{+}$was more toxic than MPTP itself in destroying dopamine containing cells. Thus, intranigral infusions of $\mathrm{MPP}^{+}$, but not MPTP, destroyed nigral neurones in rats. ${ }^{33}$ Similarly, intracerebroventricular injections of $\mathrm{MPP}^{+}$ destroyed nigral cells in the brains of mice. ${ }^{34}$ In cell culture $\mathrm{MPP}^{+}$is toxic to mesencephalic cells. ${ }^{35}{ }^{36}$ So all this data led to the conclusion that it was $\mathrm{MPP}^{+}$and not MPTP that was responsible for the toxic actions observed.

These data did not, however, explain the mechanism by which MPTP (or MPP ${ }^{+}$) killed dopamine containing cells. This issue was clarified with the discovery that $\mathrm{MPP}^{+}$induces oxidative stress owing to its ability to inhibit the oxidation of mitochondrial NAD-linked substrates. ${ }^{37}{ }^{38}$ More specifically MPP ${ }^{+}$inhibits mitochondrial energy metabolism at the level of complex $\mathrm{I}^{39}$. However, millimolar concentrations of $\mathrm{MPP}^{+}$were required in vitro to produce this effect and it was thought unlikely that these would be achieved in vivo. But $\mathrm{MPP}^{+}$is actively accumulated by mitochondria such that 50-100 times the external concentration can be achieved. ${ }^{40-42}$ So at present it is believed that MPP ${ }^{+}$ interferes with mitochondrial energy metabolism somewhere between NADH dehydrogenase and coenzyme $Q 10 .^{43}$ Exactly how and where this occurs remains unknown. Nevertheless, its consequences can be observed in terms of depletion of cellular ATP, a decrease in reduced glutathione content, and alterations in cellular calcium content. ${ }^{446}$

Free radical generation as a mechanism of MPTP toxicity

One basic mechanism initially proposed to explain the neurotoxic actions of $\mathrm{MPP}^{+}$was the production of free radicals. This was derived from the chemical similarity between $\mathrm{MPP}^{+}$and a paraquat, a known redox cycler. Although $\mathrm{MPP}^{+}$bears a striking chemical resemblance to paraquat, $\mathrm{MPP}^{+}$is extremely stable compared with paraquat and does not undergo single electron reduction to produce oxygen radicals. ${ }^{47}{ }^{48}$ This is emphasised by the electrochemical potential of $\mathrm{MPP}^{+}$of $<1.0 \mathrm{~V}$ which compared with paraquat makes it improbable that it will undergo bioreduction to stimulate toxic oxygen radical formation. ${ }^{49}$ However, this conclusion presumes that it is $\mathrm{MPP}^{+}$alone which causes the neurotoxicity associated with MPTP administration.

MPTP is converted to $\mathrm{MPP}^{+}$in a two-stage reaction via the intermediate dihydropyridine derivative, MPDP $^{+} .^{50-52}$ This sequence of events gives more scope for the production of oxygen species. Indeed, there is recent evidence that oxygen radicals may be involved in the toxicity of MPTP in a manner previously unsuspected. Thus, in aerobic mitochondrial preparations MPTP stimulated an electron spin resonance (ESR) signal compatible with free radical formation..$^{53}$ This signal was prevented by inclusion of superoxide dismutase suggesting the generation of superoxide radicals. The metabolism of MPTP appeared involved since the ESR signal was prevented by the inclusion of the MAO B inhibitor deprenyl but not by the MAO A inhibitor clorgyline. In the absence of mitochondria neither of the MPTP metabolites, $\mathrm{MPP}^{+}$or MPDP ${ }^{+}$, alone produced an ESR signal. However, together they caused a spectrum which increased in intensity with time. These data suggest a redox reaction occurs between $\mathrm{MPP}^{+}$and $\mathrm{MPDP}^{+}$to produce toxic oxygen radicals and that these may be involved in the ability of MPTP to destroy nigral containing cells. Whether an action of MPTP based on superoxide formation is compatible with inhibition of mitochondrial function remains to be determined.

So the MPTP story reveals possible mechanisms by which nigral dopamine containing cells may be destroyed. But what is its relevance to Parkinson's disease? It may be that there is an MPTP like toxin involved as a cause of Parkinson's disease although at present this appears unlikely. On the other hand, it may be that the mechanism by which MPTP kills dopamine cells by interference with mitochondrial function or by superoxide formation may reflect a selective vulnerability of dopamine cells in substantia nigra which is also apparent in idiopathic Parkinson's disease. So, are there any similarities between the actions of MPTP and biochemical changes occurring in brain in Parkinson's disease itself?

\section{Evidence for a neurotoxic process occurring in brain in} Parkinson's disease

One approach to detecting a cause or mechanism 
underlying idiopathic Parkinson's disease is to examine post-mortem brain tissue. However, success depends partially on how cell death in Parkinson's disease occurs. For example, if Parkinson's disease occurs as a result of some fault in utero or due to a single toxic insult during life then there might be no indication of a toxic process in the post-mortem tissues from patients at the end stage of their disease. Nevertheless, we have examined some general indicators of cellular toxicity in post-mortem tissues from patients dying with Parkinson's disease.

The tissues from these studies came from patients with a history of idiopathic Parkinson's disease all of whom received levodopa treatment up to the time of death and whose brain showed evidence of cell loss and the presence of Lewy bodies in substantia nigra and a markedly decreased caudate dopamine content. These tissues were matched with tissues from control patients of similar age who died from nonneurological and non-psychiatric disorders and whose substantia nigra appeared normal in histological examination. The tissues were also matched for the time between death and body refrigeration and the time between death and autopsy and subsequent freezing of the brain material.

Initially, we assessed markers of lipid peroxidation as a non-specific index of cell death..$^{55}$ Two parameters were studied, namely, the brain content of polyunsaturated fatty acids (PUFA), the substrate for lipid peroxidation, and the content of malondialdehyde, a stable intermediate in the process of lipid peroxidation (table 1). The PUFA content of substantia nigra was reduced compared to levels found in control brain tissue and this change was selective to substantia nigra since no difference in PUFA content was found in any other brain region examined. So it appeared that perhaps increased degradation of PUFAs was occurring in Parkinsonian nigra. This view was confirmed by the finding of an increased basal level of malondialdehyde in Parkinsonian substantia nigra compared to control tissue which again did not occur in any other brain region examined. These data suggest that even at the end stage of Parkinson's disease there is evidence for some ongoing toxic process such as might occur due to free radical attack. It should be noted that all the patients examined received levodopa until the time of death and it cannot be excluded that the changes observed were not due to drug treatment. However, since levodopa accumulates in many brain regions it might be expected that similar changes would be observed elsewhere, particularly within the caudate-putamen where levodopa occurs in high amounts.

If there is some on-going toxic process occurring within the Parkinsonian brain then what could be the stimulating factor? It could be some environmental
Table 1 Polyunsaturated fatty acid (PUFA) and basal $M D A$ levels in the substantia nigra and cerebellum of Parkinsonian and control human brains

\begin{tabular}{|c|c|c|c|}
\hline Brain region & $\begin{array}{l}\text { PUFA's } \\
\text { (nmol linoleic } \\
\text { acid/mg } \\
\text { protein) }\end{array}$ & $\begin{array}{l}\text { Basal } M D A \\
\text { levels (nmol } \\
M D A / m g \\
\text { protein) }\end{array}$ & $\begin{array}{l}\text { Ratio basal } \\
M D A / P U F A ' s \\
\left(\times 10^{-3}\right)\end{array}$ \\
\hline $\begin{array}{l}\text { Cerebellum } \\
\text { Control }(n=13) \\
\text { Parkinsonian } \\
\quad(n=10)\end{array}$ & $186(10)$ & $4.2(0.4)$ & $21 \cdot 0(1 \cdot 6)$ \\
\hline $\begin{array}{l}\text { Substantia nigra } \\
\text { Control }(n=19) \\
\text { Parkinsonian } \\
\quad(n=14)\end{array}$ & $254(14)^{*}$ & $2 \cdot 7(0.3)^{*}$ & $11 \cdot 2(1 \cdot 2)^{*}$ \\
\hline
\end{tabular}

Values are expressed as means (SEM). *p $<0.05$ compared with control tissue (Student's t test). Data taken from Dexter et al. ${ }^{\text {s4 } s s}$

toxin such as MPTP but so far none has been identified. On the other hand, some endogenous agent might act to stimulate free radical formation. In this respect we decided to investigate the iron content of the Parkinsonian brain since iron is able to stimulate oxygen radical formation..$^{56}$ Indeed, in 1968 Earle $^{57}$ had suggested an increase in brain iron content in Parkinson's disease using formalin fixed tissues examined by X-ray fluorescent spectroscopy.

The total iron content of the Parkinsonian brain was measured compared with age-matched controf tissue using inductively coupled plasma spectros copy. ${ }^{58} 59$ This showed that within the substantia nigra as a whole and also within the zona compacta of substantia nigra there was a substantial increase in total iron content (fig). No increase in iron levels was. found in any other brain area examined although there was a reduction in iron content within the medial and lateral segments of the globus pallidus. So there appeared to be a specific increase in iron within that area of the brain which is thought to bear the primary pathological change in Parkinson's disease. Recently, the finding of an increased iron content of substantia nigra in Parkinson's disease was confirmed by others. ${ }^{60}$ At this point it should be noted that we also found a large increase in the zinc content of substantia nigra although this also occurred in caudate-putamen and so was not therefore specifically related to path ological change. In addition, the copper content of substantia nigra was reduced. There were no changes in the levels of manganese or lead in any of the brain areas examined when compared to control tissues.

Once again, the issue of drug treatment must be considered as being relevant to the changes in brain iron content. However, any effect of drug treatment would appear unlikely since the samples examined by Earle in 1968 were collected between 1867 and 1954, in other words prior to the levodopa era. ${ }^{57}$

One interpretation of the data so far would be that enhanced levels of iron within substantia nigra . 


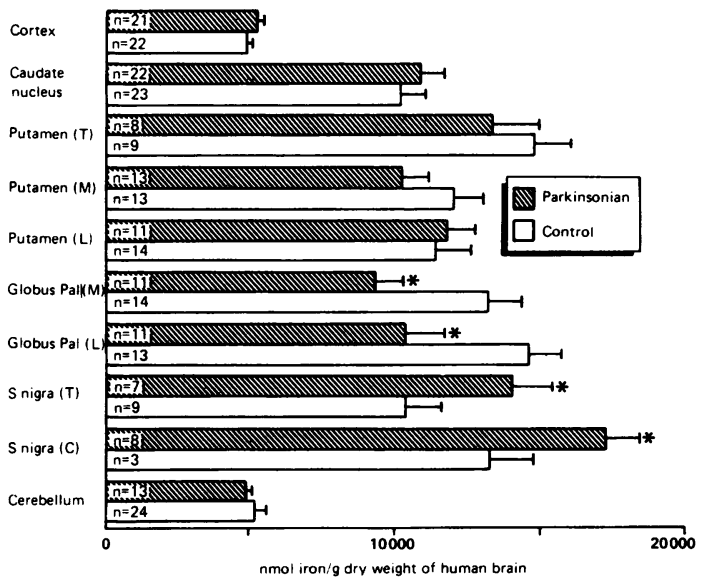

Fig Total levels of iron ( $\mathrm{nmol} / \mathrm{g}$ dry weight) in Parkinsonian and age-matched control human necropsy brains. Values represent mean and 1 SEM.* $p<0.05$ compared with controls (Student's t test). Key: (C) $=$ Compacta; $(T)=$ Total; $L=$ Lateral; (M) $=$ Medial. Taken from Dexter et al..$^{59}$

stimulate free radical formation leading to enhanced lipid peroxidation and accelerated dopamine cell death. However, not all forms of iron are potentially toxic and it would be necessary for the increase in iron to be present in a reactive form. Indeed, the brain protects itself against the toxic actions of iron by incorporating it into ferritin. The normal physiological response to an increase in iron is stimulation of a specific m-RNA for ferritin formation. However, surprisingly, in our studies there was no increase in brain ferritin content in substantia nigra, rather there was a generalised decrease in ferritin throughout the Parkinsonian brain when compared with levels found in age-matched control tissues. ${ }^{61}$ These data suggest at least that there may be some subtle alteration in iron handling within the brain in Parkinson's disease.

Another interpretation of the increased iron content of substantia nigra in Parkinson's disease is that it is a

Table 2 Superoxide dismutase (SOD) activity in substantia nigra and cerebellum of Parkinsonian patients and normal controls

\begin{tabular}{lllllll}
\hline $\begin{array}{lllll}\text { Brain } \\
\text { area }\end{array}$ & $\begin{array}{l}\text { Disease } \\
\text { category }\end{array}$ & $n$ & \multicolumn{3}{l}{ Total } & \multicolumn{2}{l}{$\begin{array}{l}\text { U/g wet weight } \\
\text { Sytosolic }\end{array}$} & $\begin{array}{l}\text { Particulate } \\
\text { SOD }\end{array}$ & SOD \\
\hline Cerebellum & $\begin{array}{l}\text { Control } \\
\text { Parkinsonian }\end{array}$ & 11 & $955(19)$ & $711(20)$ & $127(3)$ \\
$\begin{array}{l}\text { Substantia } \\
\text { nigra }\end{array}$ & $\begin{array}{l}\text { Control } \\
\text { Parkinsonian }\end{array}$ & 11 & $1344(23)$ & $139(15)$ & $120(4)$ \\
\hline
\end{tabular}

Values are expressed as means (SEM). *p $<0.05$ compared, with control tissues (Student's $t$ test). Data from Saggu et al..$^{66}$ consequence of the neurodegenerative process rather than a cause. For this reason, it is necessary to determine whether the increase in iron is specific to Parkinson's disease or whether it occurs in other neurodegenerative disease affecting basal ganglia. In brain tissue from patients dying with multiple system atrophy and progressive supranuclear palsy the iron content of substantia nigra was also increased (unpublished data). However, in progressive supranuclear palsy there was a corresponding increase in the level of ferritin suggesting the physiological trigger to increased iron was intact. The ferritin content of brain in multiple system atrophy remains to be measured.

So, it may be that the alteration in iron handling as a whole is specific to Parkinson's disease and that changes in physiological responses to altered iron levels contribute to the pathological changes occurring in this disorder particularly within substantia nigra.

\section{Altered mitochondrial function in idiopathic Parkin- son's disease}

The post mortem data presented above suggests that there are reasons for believing an on-going toxic process may occur within the Parkinsonian brain. However, what remains unresolved is whether there is any link between the susceptibility of nigral dopamine cells to the neurotoxic actions of MPTP and the pathological process occurring in idiopathic Parkinson's disease. It might be expected that if free radical formation was enhanced in Parkinson's disease this would be compensated for by alterations in protective mechanisms. Alternatively, it might be that the protective systems in the substantia nigra fail. Indeed, small decreases in the levels of glutathione peroxidase catalase and reduced glutathione have been found within Parkinsonian substantia nigra. ${ }^{62-65}$ However, superoxide dismutase (SOD) is of particular interest in this respect since it occurs as two iso-enzymes, one of which is a copper-zinc dependent cytosolic form while the other is the manganese dependent particulate form largely associated with mitochondria. There are no differences in total SOD activity in substantia nigra and cerebellum and Parkinson's disease compared with control subjects. ${ }^{66}$ Similarly, we found no difference in the activity of the cystolic form of SOD but there was an increase in the activity of the particulate form of SOD in Parkinsonian substantia nigra, but not cerebellum, compared with control tissues. (At this point it should be noted that Matilla and colleagues ${ }^{67}$ also recently reported an increase in SOD activity in substantia nigra in Parkinson's disease. However, the increase was apparent in the cytosolic form of the enzyme rather than in the mitochondrial form. So although we are agreed that there is an increase in SOD activity in Parkinson's disease, there is a discrepancy as to which form of the 
enzyme is implicated.) Our data raise the tantalising concept that in Parkinson's disease mitochondria may be under attack from superoxide, so providing a link with ideas on MPTP toxicity.

If mitochondrial superoxide dismutase activity is enhanced in Parkinson's disease then does this suggest some underlying fault in mitochondria as a cause of the disorder? Very recently Schapira and colleagues ${ }^{68}$ assessed mitochondrial function in substantia nigra of the Parkinsonian brain. Rotenone sensitive mitochondrial NADH cytochrome $\mathrm{c}$ reductase activity (complex I and III) was reduced in Parkinsonian nigra compared with control tissues while succinate cytochrome $\mathrm{c}$ reductase activity (complex II and III) was unchanged. Levels of a non-respiratory mitochondrial enzyme, citrate synthase, and a non-mitochondrial enzyme, rotenone insensitive NADH cytochrome c reductase were unaffected. So the results suggest an impairment of complex I of the mitochondrial respiratory chain in Parkinson's disease. The similarity to alterations occurring in the presence of MPTP is striking.

\section{Conclusions}

The discovery of the neurotoxic actions of MPTP on substantia nigra has provided ideas on how the toxicity to these cells might involve inhibition of mitochondrial energy metabolism and/or superoxide radical generation. This has stimulated the idea that a toxin or a continuous toxic process may be responsible for the pathological changes which occur in Parkinson's disease. Indeed, examination of post-mortem Parkinsonian tissues appear to indicate that a continuing toxic process may indeed occur in substantia nigra in Parkinson's disease and that potentially this may be related to alterations in iron handling in this disorder. The changes in superoxide dismutase activity suggest that it may be the production of superoxide radicals which lead to cellular damage and in this respect there are striking similarities to the recent findings of free radical formation due to a redox reaction between metabolites of MPTP. Our findings of a selective increase in mitochondrial superoxide dismutase activity raises once again the concept that it may be alterations in mitochondrial function that is a primary cause of cell death in Parkinson's disease. Indeed, the recent finding of Schapira and colleagues of inhibition of complex I in Parkinson's disease provides a tantalising link between the MPTP story and the idiopathic disorder. It may be that MPTP will lead us closer to discovering the cause of Parkinson's disease than was at first thought.

These investigations were funded by the Parkinson's Disease Society, the Medical Research Council and the Research Funds of the Bethlem Royal and Maudsley Hospitals.

\section{References}

1 Forno LS. Pathology of Parkinson's disease. In: Marsden CD, Fahn S, eds. Neurology, 2: Movement Disorders. London: Butterworth Scientific, 1981:25-40.

2 Hornykiewicz $\mathrm{O}$. Brain neurotransmitter changes in Parkinson's disease. In: Marsden CD, Fahn S, eds. Neurology, 2: Movement Disorders. London: Butterworth Scientific 1981:41-58.

3 Agid Y, Javoy-Agid F, Ruberg M. Biochemistry of neurotransmitters in Parkinson's disease. In: Marsden CD, Fahn S, eds. Movement Disorders 2. London: Butterworth, 1987:166-230.

4 Davis GC, Williams AC, Markey SP, Ebert MH, Caine ED, Reichert CM, Kopin IJ. Chronic Parkinsonism secondary to intravenous injection of meperidine analogues. Psychiatry Res 1979;1:249-54.

5 Langston JW, Ballard P, Tetrud JW, Irwin I. Chronic parkinsonism in humans due to a product of meperidine analog synthesis. Science 1982;219:979-80.

6 Ballard PA, Tetrud JW, Langston JW. Permanent human parkinsonism due to 1-methyl-4-phenyl-1,2,3,6-tetrahydropyridine (MPTP). Neurology 1985;35:949-56.

7 Burns RS, Chiueh CC, Markey SP, Ebert MH, Jacobowitz DM, Kopin IJ. A primate model of parkinsonism: Selective destruction of dopaminergic neurons in the pars compacta of the substantia nigra by $\mathrm{N}$-methyl-4-phenyl-1,2,3,6-tetrahydropyridine. Proc Nat Acad Sci USA 1983;80:4546-50.

8 Langston JW, Forno LS, Rebert CS, Irwin I. Selective nigral toxicity after systemic administration of 1-methyl-4-phenyl 1,2,5,6-tetrahydropyridine (MPTP) in the squirrel monkey. Brain Res 1984;292:390-4.

9 Jenner P, Rupniak NMJ, Rose S, Kelly E, Kilpatrick G, Lees A, Marsden CD. 1-Methyl-4-phenyl-1,2,3,6-tetrahydropyridineinduced parkinsonism in the common marmoset. Neurosci Lett 1984;50:85-90.

10 Jenner P, Marsden CD. MPTP-induced parkinsonism in primates and its use in the assessment of novel strategies for the treatment of Parkinson's disease. In: Clifford Rose F, ed. Parkinson's Disease: Clinical and Experimental Advances. London: John Libbey, 87:149-62.

11 Garvey J, Petersen M, Waters CM, et al. Administration of MPTP to the common marmoset does not alter cortical cholinergic function. Movement Disorders 1986;1:129-34.

12 Jenner $\mathbf{P}$, Taquet $\mathbf{H}$, Mauborgne A, et al. Lack of change in basal ganglia neuropeptide content following subacute 1-methyl-4phenyl-1,2,3,6-tetrahydropyridine treatment of the common marmoset. J Neurochem 1986;46:1548-51.

13 Mitchel IJ, Cross AJ, Sambrook MA, Crossman AR. Sites of the neurotoxic actions of 1-methyl-4-phenyl-1,2,3,6-tetrahydropyridine in the macaque monkey include the ventral tegmental area and the locus coeruleus. Neurosic Lett 1985;61:195-200.

14 Forno LS, Langston JW, DeLanney LE, Irwin I, Ricaurte GA. Locus ceruleus lesions and eosinophilic inclusions in MPTPtreated monkeys. Ann Neurol 1986;20:449-55.

15 Forno LS, Langston JW, DeLanney LE, Irwin I. An electron microscopic study of MPTP-induced inclusion bodies in an old monkey. Brain Res 1988;448:150-7.

16 Nomoto M, Jenner P, Marsden CD. The dopamine D-2 agonist LY 141865, but not the D-1 agonist SKF 38393, reverses parkinsonism induced by 1-methyl-4-phenyl-1,2,3,6-tetrahydropyridine (MPTP) in the common marmoset. Neurosci Let 1985;57:37-41.

17 Nomoto M, Jenner P, Marsden CD. The D-1 agonist SKF 38393 inhibits the antiparkinsonian activity of the D-2 agonist LY 171555 in the MPTP-treated marmoset. Neurosci Lett 1988;93:275-80. 
18 Nomoto M, Stahl S, Jenner P, Marsden CD. Antiparkinsonian activity of (+)-PHNO in the MPTP-treated common marmoset. Movement Disorders 1987;2:37-45.

19 Temlett JA, Chong PN, Oertel WH, Jenner P, Marsden CD. The D-1 dopamine receptor partial agonist, CY 208-243, exhibits antiparkinsonian activity in the MPTP-treated marmoset. Eur $J$ Pharmacol 1988;156:197-206.

20 Bedard PJ, Di Paolo T, Falardeau P, Boucher R. Chronic treatment with L-DOPA but not bromocriptine induced dyskinesia in MPTP-parkinsonian monkeys. Correlation with $\left[{ }^{3} \mathrm{H}\right] \mathrm{sp}-$ iperone binding. Brain Res 1986;379:294-9.

21 Crossman AR, Clarke CE, Boyce S, Robertson RG, Sambrook MA. MPTP-induced parkinsonism in the monkey: Neurochemical pathology, complications of treatment and pathophysiology mechanisms. Can J Neurol Sci 1987;14:428-35.

22 Redmond DE, Roth RH, Elsworth JD, et al. Fetal neuronal grafts in monkeys given methylphenyltetrahydropyridine. Lancet 1986;ii: 1125-7.

23 Fine A, Oertel WH, Hunt SP, et al. Transplantation of embryonic marmoset dopaminergic neurons to the corpus striatum of marmosets rendered parkinsonian by MPTP. In: Gash DM, Sladek JR, eds. Prog Brain Res vol 74: Transplantation into the mammalian CNS: preclinical and clinical studies. 1989 (in press).

24 Markey SP, Johannessen JN, Chiueh CC, Burns RS, Herkenham MA. Intraneuronal generation of a pyridinium metabolite may cause drug-induced parkinsonism. Nature 1984;311:464-7.

25 Johannessen JN, Chiueh CC, Burns RS, Markey SP. Differences in metabolism of MPTP in rodent and primate brain parallel differences in sensitivity to its neurotoxic effects. Life Sci 1985;36:219-24.

26 Chiba K, Trevor A, Castagnoli N. Metabolism of the neurotoxic tertiary amine, MPTP, by brain monoamine oxidase. Biochem Biophys Res Commun 1984;120:574-8.

27 Salach JI, Singer TP, Castagnoli N Jr, Trevor A. Oxidation of the neurotoxic amine 1-methyl-4-phenyl-1,2,3,6-tetrahydropyridine (MPTP) by monoamine oxidases A and B and suicide inactivation of the enzymes by MPTP. Biochem Biophys Res Commun 1984;125:831-5.

28 Heikkila RE, Manzino L, Cabbat FS, Duvoisin RC. Studies on the oxidation of the dopaminergic neurotoxin 1-methyl-4-phenyl1,2,3,6-tetrahydropyridine by monoamine oxidase B. J Neurochem 1985;45:1049-54.

29 Javitch JA, D'Amato RJ, Strittmatter SM, Snyder SH. Parkinsonism-inducing neurotoxin, $\mathrm{N}$-methyl-4-phenyl-1,2,3,6-tetrahydropyridine: Uptake of the metabolite $\mathrm{N}$-methyl-4-phenylpyridine by dopamine neurons explains selective toxicity. Proc Natl Acad Sci USA 1985;82:2173-7.

30 D'Amato RJ, Benham DF, Snyder SH. Characterization of the binding of $\mathrm{N}$-methyl-4-phenylpyridine, the toxic metabolite of the parkinsonian neurotoxin $\mathrm{N}$-methyl-4-phenyl-1,2,3,6-tetrahydropyridine to neuromelanin. J Neurochem 1987;48:653-8.

31 Heikkila RE, Manzino L, Cabbat FS, Duvoisin RC. Protection against the dopaminergic neurotoxicity of 1-methyl-4-phenyl1,2,3,6-tetrahydropyridine by monoamine oxidase inhibitors. Nature 1984;311:467-9.

32 Mayer RA, Kindt MV, Heikkila RE. Prevention of the nigrostriatal toxicity of 1-methyl-4-phenyl-1,2,3,6-tetrahydropyridine by inhibitors of 3, 4-dihydroxyphenylethylamine transport. $J$ Neurochem 1986;47:1073-9.

33 Bradbury AJ, Costall B, Domeney AM, et al. 1-Methyl-4-phenylpyridine is neurotoxic to the nigrostriatal dopamine pathway. Nature 1986;319:56-7.

34 Bradbury AJ, Costall B, Jenner PG, Kelly ME, Marsden CD, Naylor RJ. The neurotoxic actions of 1-methyl-4-phenylpyridine $\left(\mathrm{MPP}^{+}\right)$are not prevented by deprenyl treatment. Neurosci Lett 1985;58:177-81.

35 Sanchez-Ramos J, Barrett JN, Goldstein M, Weiner WJ, Hefti F. 1-Methyl-4-phenylpyridinium $\left(\mathrm{MPP}^{+}\right.$) but not 1-methyl-4phenyl-1,2,3,6-tetrahydropyridine (MPTP) selectively destroys dopaminergic neurons in cultures of dissociated rat mesencephalic neurons. Neurosci Lett 1986;72:215-20.
36 Mytilineou C, Cohen G, Heikkila RE. 1-Methyl-4-phenylpyridine $\left(\mathrm{MPP}^{+}\right)$is toxic to mesencephalic dopamine neurons in culture. Neurosci Lett 1985;57:19-24.

37 Johannessen JN, Adams JD, Schuller HM, Bacon JP, Markey SP. 1-Methyl-4-phenylpyridine (MPP $\left.{ }^{+}\right)$induces oxidative stress in the rodent. Life Sci 1986;38:743-9.

38 Nicklas WJ, Vyas I, Heikkila RE. Inhibition of NADH-linked oxidation in brain mitochondria by 1-methyl-4-phenylpyridine, a metabolite of the neurotoxin, 1-methyl-4-phenyl1,2,3,6-tetrahydropyridine. Life Sci 1985;36:2503-8.

39 Vyas I, Heikkila RE, Nicklas WJ. Studies on the neurotoxicity of 1-methyl-4-phenyl-1,2,3,6-tetrahydropyridine: Inhibition of NAD-linked substrate oxidation by its metabolite, 1-methyl-4phenylpyridinium. $J$ Neurochem 1986;46:1501-7.

40 Ramsay RR, Singer TP. Energy-dependent uptake of N-methyl-4phenylpyridinium, the neurotoxic metabolite of 1-methyl-4phenyl-1,2,3,6-tetrahydropyridine, by mitochondria. $J$ Biol Chem 1986;261:7585-7.

41 Ramsay RR, Dadgar J, Trevor A, Singer TP. Energy-driven uptake of $\mathrm{N}$-methyl 4-phenylpyridine by brain mitochondria mediates the neurotoxicity of MPTP. Life Sci 1986;39:581-8.

42 Ramsay RR, Salach JI, Singer TP. Uptake of the neurotoxin 1methyl-4-phenylpyridine (MPP ${ }^{+}$) by mitochondria and its relation to the inhibition of the mitochondrial oxidation of $\mathrm{NAD}^{+}$-linked substrates by $\mathrm{MPP}^{+}$. Biochem Biophys Res Commun 1986;134:743-8.

43 Singer TP, Castagnoli N Jr, Ramsay RR, Trevor AJ. Biochemical events in the development of parkinsonism induced by 1 methyl-4-phenyl-1,2,3,6-tetrahydropyridine. $J$ Neurochem 1987;49:1-8.

44 Di Monte D, Jewell SA, Ekstrom G, Sandy MS, Smith MT. 1methyl-4-phenyl-1,2,3,6-tetrahydropyridine (MPTP) and 1methyl-4-phenylpyridine ( $\left.\mathrm{MPP}^{+}\right)$cause rapid ATP depletion in isolated hepatocytes. Biochem Biophys Res Commun 1986;137:310-5.

45 Kass GEN, Wright JM, Nicotera P, Orrenius S. The mechanism of 1-methyl-4-phenyl-1,2,3,6-tetrahydropyridine toxicity: Role of intracellular calcium. Arch Biochem Biophys 1988;260:789-97.

$46 \mathrm{Di}$ Monte D, Sandy MS, Smith MT. Increased efflux rather than oxidation is the mechanism of glutathione depletion by 1methyl-4-phenyl-1,2,3,6-tetrahydropyridine (MPTP). Biochem Biophys Res Commun 1987;148:153-60.

47 Di Monte D, Sandy MS, Ekstrom G, Smith MT. Comparative studies on the mechanisms of paraquat and 1-methyl-4-phenylpyridine $\left(\mathrm{MPP}^{+}\right.$) cytotoxicity. Biochem Biophys Res Commun 1986;137:303-9.

48 Frank DM, Arora PK, Blumer JL, Sayre LM. Model study of the bioreduction of paraquat, $\mathrm{MPP}^{+}$, and analogs. Evidence against a "redox cycling" mechanism in MPTP neurotoxicity. Biochem Biophys Res Commun 1987;147:1095-104.

49 Sayre LM, Arora PK, Feke SC, Urback FL. J Am Chem Soc 1986;108:2464-6.

50 Castagnoli N Jr, Chiba K, Trevor AJ. Potential bioactivation pathways for the neurotoxin 1-methyl-4-phenyl-1,2,3,6-tetrahydropyridine (MPTP). Life Sci 1985;36:225-30.

51 Peterson LA, Caldera PS, Trevor A, Chiba K, Castagnoli N Jr. Studies on the 1-methyl-4-phenyl-2,3-dihydropyridinium species $2,3-\mathrm{MPDP}^{+}$, the monoamine oxidase catalyzed oxidation product of the nigrostriatal toxin 1-methyl-4-phenyl1,2,3,6-tetrahydropyridine (MPTP). J Med Chem 1985; 28: $1432-6$.

52 Trevor AJ, Castagnoli N Jr, Caldera P, Ramsay RR, Singer TP. Bioactivation of MPTP: Reactive metabolites and possible biochemical sequelae. Life Sci 1987;40:713-9.

53 Rossetti ZL, Sotgiu A, Sharp D, Hadjiconstantinou M, Neff NH. 1-Methyl-4-phenyl-1,2,3,6-tetrahydropyridine (MPTP) and free radicals in vitro. Biochem Pharmacol 1988;37:4573-4.

54 Dexter DT, Carter C, Agid F, et al. Lipid peroxidation as a cause of nigral cell death in Parkinson's disease. Lancet 1986;ii: $639-40$.

55 Dexter CT, Carter CJ, Wells FR, et al. Basal lipid peroxidation in 
substantia nigra is increased in Parkinson's disease. $J$ Neurochem 1989;52:381-9.

56 Halliwell B, Gutteridge JMC. Free Radicals in Biology and Medicine. Oxford: Clarendon Press, 1985.

57 Earle KM. Studies in Parkinson's disease including X-ray fluorescent spectroscopy of formalin fixed brain tissue. $J$ Neuropathol Exp Neurol 1968;27:1-14.

58 Dexter DT, Wells FR, Agid F, Agid Y, Lees AJ, Jenner P, Marsden CD. Increased nigral iron content in post-mortem parkinsonian brain. Lancet 1987;ii:1219-20.

59 Dexter DT, Wells FR, Lees AJ, Agid F, Agid Y, Jenner P, Marsden CD. Increased nigral iron content, and alterations in other metal ions occurring in brain in Parkinson's disease. $J$ Neurochem 1989 (in press).

60 Sofic E, Riederer P, Heinsen H, Beckmann H, Reynolds GP, Hebenstreit G, Youdim MBH. Increased iron (III) and total content in post mortem substantia nigra of parkinsonian brain. J Neural Transm 1988;74:199-205.

61 Dexter DT, Carayon A, Vidailhet M, Ruberg M, Agid F, Agid Y, Lees AJ, Wells FR, Jenner P, Marsden CD. Decreased ferritin levels in brain in Parkinson's disease. (in preparation).

62 Ambani C, Van Woert MH, Murphy S. Brain peroxidase and catalase in Parkinson's disease. Arch Neurol 1975;32:114-8.

63 Kish SJ, Morito CH, Hornyikiewicz O. Glutathione peroxidase activity in Parkinson's disease brain. Neurosci Lett 1985;58:343-6.

64 Perry TL, Godin DV, Hansen S. Parkinson's disease: A disorder due to nigral glutathione deficiency. Neurosci Lett 1982;33: 305-10.

65 Perry T, Yong VW. Idiopathic Parkinson's disease, progressive supranuclear palsy and glutathione metabolism in the substantia nigra of patients. Neurosci Lett 1986;67:269-74.

66 Saggu H, Cooksey J, Dexter D, Wells FR, Lees A, Jenner P, Marsden CD. A selective increase in particulate superoxide dismutase activity in parkinsonian substantia nigra. $J$ Neurochem 1989 (in press)

67 Marttila RJ, Lorentz H, Rinne UK. Oxygen toxicity protecting enzymes in Parkinson's disease. Increased superoxide dismutase-like activity in the substantia nigra and basal nucleus. $J$ Neurol Sci 1988;86:321-31.

68 Schapira AHV, Cooper JM, Dexter D, Jenner P, Clark JB, Marsden CD. Mitochondrial complex I deficiency in Parkinson's disease. (in preparation). 